\title{
Metaenunciação: uma questão de interdiscurso e de relevância*
}

\author{
Sírio Possenti \\ Universidade Estadual de Campinas
}

\section{Abstract}

This paper discusses the fundamental difference between pragmatics and discourse analysis (French line) in relation to the metaenunciation or comments in the discourse about the discourse itself. This difference involves the concepts of "circumstances" and "production conditions". It will be seen that both theories refer to each other in a reductionist way and that certain facts could be understood better if the discourse analysis considered circumstantial aspects which, from this point of view, are relevant only for pragmatics. 


\section{O PROBLEMA}

$\mathrm{P}$ oder-se-ia dizer que a Análise do Discurso Francesa (doravante, $\mathrm{AD}^{1}$ ) nasce de uma ruptura com a pragmática - para empregar um termo dos mais caros ao círculo a que pertencem certamente os principais praticantes dessa corrente, adeptos da chamada epistemologia francesa (basta ver o destaque freqüente da coupure saussuriènne). Mais especificamente, a AD se constitui sob os auspícios da epistemologia althusseriana, caracterizada fortemente pela concepção segundo a qual a ruptura inclui inevitavelmente a caracterização da etapa anterior como ideológica. Ou seja, uma ciência se constitui simultaneamente pela ruptura com um estágio anterior e pela demonstração de que esse estágio não era científico. O protótipo é evidentemente Galileu, mas Marx não deixou por menos, como se tenta demonstrar em Lire Le Capital (ALTHUSSER \& BALIBAR, 1969). Uma boa súmula desta posição pode ser vista nas "Definições" de Pêcheux e Balibar, em PÊCHEUX \& FICHANT (1969). ${ }^{2}$

Se lemos PÊCHEUX (1969:75) à luz desses parâmetros, teremos que considerar crucial a passagem na qual o autor afirma que o estudo dos processos discursivos supõe duas ordens de pesquisa, uma das quais será

\footnotetext{
"o estudo da ligação entre as 'circunstâncias' de um discurso - que chamaremos daqui em diante suas condições de produção - e seu processo de produção. Esta perspectiva está representada na lingüística atual pelo papel dado ao contexto ou à situação, como pano de fundo específico dos discursos, que torna possível sua formulação e sua compreensão: é este aspecto da questão que vamos tentar esclarecer agora, através do exame crítico do conceito saussuriano de instituição."
} 
Não escaparão ao leitor dois temas fundamentais da citação: a) a afirmação de que o conceito de circunstância será substituído pelo de condições de produção - substituição cuja finalidade é exatamente retirar o funcionamento do discurso da cena pragmática, para inseri-lo nas instâncias enunciativas institucionais, marcadas por características amplamente históricas. Trata-se exatamente de uma ruptura com o modo de considerar as "circunstâncias do discurso" ou, como se dirá depois, o exterior específico dos discursos; b) a afirmação de que esta perspectiva está representada na "lingüística atual" pelos conceitos de contexto e de situação. Dizer que a "lingüística atual" considera esta questão através de conceitos que a $\mathrm{AD}$ não simplesmente substitui, mas com os quais rompe, significa dizer, de alguma maneira, que esta versão será considerada, a partir de agora, como uma etapa anterior, ideológica, "não científica" da lingüistica. Ou seja, num golpe, a pragmática é declarada uma etapa superada (com muito boas razões, diga-se de passagem, de vez que passa ao largo de todos os efeitos dos discursos de Marx e de Freud) e é substituída pela Análise do Discurso. Desses dois acontecimentos, muitos nem se deram conta, infelizmente...

Mas não nos enganemos: se a $\mathrm{AD}$ atira nas circunstâncias, é para acertar o sujeito. Sabemos que, nas principais correntes pragmáticas - as ligadas às regras conversacionais e as ligadas à teoria dos atos de fala - o papel do sujeito, seja ele chamado de falante, de locutor, de enunciador, etc., é crucial: é sua intenção que deve ser descoberta, ou seja, o sentido de um texto é, no fundo, o "sentido do autor" (speaker's meaning). Quando não se tem acesso ao sentido pela consideração exclusiva do material verbal, recorre-se a um aparato que inclui de forma não-aleatória um conjunto de fatores relevantes da circunstância, do contexto. É através deles e/ou de sua combinação com o que é dito que se tem acesso à intenção do locutor.

Na verdade, as diversas pragmáticas não tematizam explicitamente a questão do sujeito, como o faz insistentemente a AD. Mas isso não significa que não se trata de uma questão relevante, mas sim 
que se trata de uma questão considerada não-problemática. Como diz Ducrot, “... as pesquisas sobre linguagem, há pelo menos dois séculos, consideram como óbvio - sem sequer cogitar em formular a idéia, de tal modo ela se mostra evidente - que cada enunciado possui um e somente um autor" (1984: 161). Trata-se, nos termos do próprio autor, do pressuposto da unicidade do sujeito (que a $\mathrm{AD}$ contesta, mais especificamente pelo viés da psicanálise, mais genericamente pelo das variadas versões da polifonia). Ducrot resume a caracterização do sujeito da pragmática através dos seguintes traços: a) ser dotado das capacidades psico-fisiológicas necessárias para a produção dos enunciados; b) ser o autor, a origem dos atos ilocucionários realizados na produção dos enunciados; c) ser designado por marcas de primeira pessoa (p.178-79).

É difícil sustentar que o locutor controla seu discurso, se se aceita que este provém da história (e dos outros discursos, etc) e é regrado por instituições que têm seu próprio funcionamento, independentemente dos sujeitos que nelas se inscrevem. Mas a assunção não parece tão problemática se os determinantes exteriores do discurso forem os da circunstância, facilmente reconhecíveis, por serem relativamente pouco numerosos, por se repetirem na forma de scripts, frames... Uma coisa é assumir que um discurso provém de um "retorno às coisas" ou da interação face a face, bem outra é assumir que ele decorre de um "trabalho sobre outros discursos" (MAINGUENEAU, 1987: 120).

\section{UM SUJEITO NEM LIVRE NEM ASSUJEITADO}

O objetivo deste trabalho é retomar de alguma forma este debate, que considero inconcluso. Sustento que a ruptura com a pragmática por parte da $\mathrm{AD}$ representou também o abandono de uma parte dos problemas, e não apenas de uma determinada maneira de solucioná-los, como parece pretender a AD. Quereria mostrar especialmente que o abandono absoluto da noção de circunstância é desnecessário, podendo mesmo representar um 
equívoco, tanto do ponto de vista empírico quando do ponto de vista teórico. Seria mais adequado incluir a circunstância - ou melhor, características específicas das circunstâncias - no próprio quadro da história, ao invés de caracterizá-la apenas sociologicamente (e de, em conseqüência, caracterizar o sujeito apenas do ponto de vista psicológico - no fundo, cognitivo). Em suma, e de acordo com a própria epistemologia à qual a $\mathrm{AD}$ se filia, ${ }^{3}$ a teoria que supera a anterior, através de uma ruptura, pode incluir as soluções relevantes da teoria anterior, não mais nos seus termos, evidentemente, mas nos termos da teoria "vencedora". Mais especificamente, o que proponho é que a teoria possa incluir a história que se dá na própria instância do discurso, e não apenas a história que explica a instância do discurso. Daria conta do efetivo processo discursivo, seu objetivo declarado.

Colocar em questão a exclusão pura e simples da circunstância exige colocar em questão a exclusão pura e simples de certas propriedades dos sujeitos - em especial um certo papel para a intenção e para um certo nível de conhecimento. Mesmo no interior da $\mathrm{AD}$, a questão do sujeito não está resolvida, como era de esperar, especialmente pelo fato de que convivem em tensão no interior da teoria uma versão francamente althusseriana (que supõe uma estrutura verdadeiramente estrutural como "origem") e uma versão lacaniana, que, bem ou mal, supõe que a estrutura tem um furo... e é exatamente lá que se inscreve o sujeito, nem por isso, no entanto, "livre", nem por isso isento de determinações, que excluem a hipótese de estar na origem de seu discurso e de ter o controle sobre seu sentido. Acrescentem-se ainda a cada vez mais relevante contribuição de Bakhtin e o fato de que nem todos (na verdade, quase ninguém) o lêem em chave psicanalítica.

Creio que uma solução interessante para a questão do sujeito pode ser formulada a partir da conjugação de dois conceitos, a meu ver francamente compatíveis: o conceito de "usuário", cunhado por CERTEAU (1990), e o de competência discursiva, proposto por MAINGUENEAU (1984). A noção de usuário tem a finalidade de 
formular uma concepção de sujeito que, sem pretender recuperar o sujeito uno da tradição filosófica ocidental - que é sem dúvida o sujeito/locutor da pragmática - nem por isso aceita considerá-lo mero efeito do que o precede e o afeta - estruturas, inconsciente, linguagem. A pretensão é dar conta do processo de que o sujeito participa, a despeito de tudo, como agente. Ou seja, embora sendo "efeito das estruturas" que o condicionam, ele é no entanto um usuário dos produtos (e dos discursos), não apenas seu consumidor.

A noção de competência discursiva proposta por MAINGUENEAU (1984), excluindo que os sujeitos sejam "ceras moles que se deixariam dominar, assujeitar" (p. 50), nem por isso restaura o sujeito todo poderoso (exatamente como em de Certeau). Sua estratégia consiste em postular que a competência discursiva do sujeito se explique não por uma superabundância de poderes do sujeito, mas pelo fato de que o número de restrições a que um discurso está submetido é pequeno. A inspiração é o conceito de competência proposto por Chomsky (evidentemente, descartada a hipótese de o discurso ser uma herança biológica, o que seria um grosseiro contrasenso), ou melhor, uma conhecida concepção de von Humboldt, especificamente através da noção de energéia: o discurso é um processo (não um produto); o processo exige processadores, por um lado, e pode ser analisado durante seu curso, por outro. Maingueneau tem em mente, entre outras coisas, não reduzir o discurso às coisas já ditas, mas entendê-lo como máquina produtora de enunciados e textos.

Pessoalmente, estou empenhado neste debate há algum tempo, ${ }^{4}$ movido pela certeza de que a pragmática (e as teorias de texto a ela associadas) perdem poder explicativo ao atribuir todas as manobras textuais a uma sagacidade talvez excessiva dos locutores, por um lado, ${ }^{5}$ e de que a $\mathrm{AD}$ também perde ao deixar de levar em conta certos ingredientes que lhe parecem irrelevantes por serem de tipo "circunstancial". A historiografia não cessa de mostrar cada vez mais claramente que mudanças resultam de acumulações (o que não é a mesma coisa que dizer que a história é cumulativa), 
que rupturas decorrem de práticas quotidianas. Se, por um lado, as rupturas escapam ao controle dos sujeitos, por outro, elas decorrem do que os sujeitos fazem. Isso se atesta tanto no domínio da ciência quanto no da economia. Tal historiografia fornece critérios que permitem evitar tanto a tentação da estrutura quanto a do sujeito autônomo.

Mas minha persistência neste debate talvez se deva a duas razões de outra ordem: uma delas se explicaria através de uma consideração sobre a natureza da polêmica, mencionada em MAINGUENEAU: "Não se polemiza a não ser contra si mesmo... para fazer calar o Outro no próprio destinador, ou, ao menos, para crer que se faz com que cale... A polêmica é apenas um meio entre outros de desembaraçar-se imaginariamente da alteridade que marca o sujeito do discurso" (CUSIN, Le discours polémique, apud MAINGUENAU, 1984:132). Sem pudor, quero dizer com isso que é provável que minha posição se deva ao fato de que avalio a $\mathrm{AD}$ como extremamente produtiva e interessante, por um lado, e por isso não quero abandoná-la; mas, por outro, parece-me que sua prática é por vezes simplificadora e tem menos a ver com "intenções de verdade" do que com organizações políticas (o que não é necessariamente negativo, além de ser inevitável). Em suma: o debate é comigo mesmo, e talvez só importe a mim mesmo. A outra razão pela qual persisti neste debate não está completamente dissociada da que acabo de mencionar, mas tem um viés específico: acredito que a posição que se assume em relação ao sujeito é em grande parte ideológica, porque aceitar que o sujeito não tem espaço de atuação implica conformar-se com o status quo, enquanto a posição contrária permite formular teoricamente e implementar praticamente alternativas ao "sistema", ao invés de sentir-se congelado por ele.

É muito provável que nem os pragmaticistas nem os analistas de discurso reconheçam suas doutrinas nesta sumária exposição. O fracasso provavelmente se deve - supondo-se que se possa excluir a simples incompetência do autor - à tentativa de expor as teses básicas da pragmática a partir da posição de analista de discurso, e 
de expor as teses da AD de uma posição que, se não é a da pragmática - gostaria que não fosse - é certamente diversa da posição de um praticante típico da AD. Se MAINGUENEAU (1984) tiver razão, sempre que se fala de um discurso "de fora", especialmente se se trata de uma posição que conflita com o referido discurso, ocorre uma interincompreensão constitutiva. Ou seja, os enunciados de um discurso são interpretados segundo os princípios (a semântica global) do outro discurso, e o resultado é sempre um simulacro. Para exemplificar de modo simples, um humanista devoto concebe o mundo como uma ordem que vai das criaturas inferiores até Deus, mas o jansenista verá nessa concepção uma mistura indevida, uma confusão. Lá onde um militante de esquerda vê movimentos sociais legítimos que põem em xeque uma ordem social injusta, o conservador verá a desordem social e a quebra da ordem jurídica (concretamente, lá onde um militante do MST vê uma ocupação, o latifundiário vê uma invasão).

\section{A METAENUNCIAÇÃO}

Tipicamente, os fatos lingüístico-discursivos aos quais se dedicam mais usualmente a pragmática e a AD estão em distribuição complementar. A pragmática (e a discourse analysis anglo-saxã) dedica-se basicamente a materiais orais obtidos em situações quotidianas de interlocução. Eventualmente, essas situações são bastante marcadas, como no caso de aulas ou de consultas médicas, e elas são tratadas como tais, mas não se reconhece nelas uma organização historicamente determinada. A AD, por seu lado, estuda particularmente textos escritos e relacionados fortemente a instituições, especialmente discursos doutrinários, que permitem não levar em conta a eventual relevância da intervenção de um sujeito singular. ${ }^{6}$

No entanto, há um conjunto de fatos aos quais ambas as vertentes se dedicam. Tanto a análise da conversação (um dos ramos da pragmática, por sua concepção de sujeito e sua forma de incluir 
as circunstâncias - ver LEVINSON, 1983) quanto a AD levam em conta "repetições", "paráfrases", "enunciados parentéticos", "metaenunciações". Em suma, enunciados, partes de enunciados ou de textos nos quais se interrompe um suposto fio homogêneo do discurso e se faz, de alguma forma, um comentário sobre elementos do próprio texto (uma palavra, um enunciado), sobre os interlocutores ou sobre a própria circunstância da enunciação. O interesse provocado por esse tipo de material acaba colocando à disposição do estudioso tanto formas claras de demarcação entre essas diferentes abordagens quanto uma ocasião para testar as teorias concorrentes.

Os analistas de discurso chamam de metaenunciação ao processo pelo qual os locutores "comentam" aquilo mesmo que dizem. Tais enunciações têm a função de marcar "não coincidências", seja entre locutores (dois locutores não empregariam as mesmas palavras), seja entre discursos (já que um discurso pode ser afetado por outro), seja entre as palavras e as coisas (as palavras seriam "incapazes" de nomear de forma transparente), seja das palavras consigo mesmas (as palavras podem ter mais de um sentido). Maingueneau estabelece com clareza as diferenças entre a pragmática e a $\mathrm{AD}$ a propósito de tais fatos:

"De um ponto de vista ingênuo 7 , o metadiscurso é apenas um conjunto de acréscimos contingentes destinados a retificar a trajetória da enunciação, colocá-la em conformidade com as intenções do locutor. A AD, em geral, lida com textos cuja produção é relativamente bem controlada, de forma que, com freqüência, $o$ metadiscurso mostra-se como tal, a derrapagem verbal produz sentido. Longe de ser um procedimento para corrigir falhas na comunicação, ele constitui um sintoma e deve ser apreendido através deste estatuto..." (MAINGUENEAU, 1987: 94).

Authier-Revuz, bem mais empenhada na disputa contra a pragmática, marca ainda mais claramente a diferença entre as abordagens:

"A consideração dos fatos metaenunciativos, com o que eles implicam de auto-representação do dizer (...) coloca de modo 
especificamente agudo a questão da escolha dos exteriores teóricos, relativos à questão do sujeito e de sua relação com a linguagem, nos quais se apóia a descrição: a linha de fratura fundamental que passa entre o sujeito-origem - da psicologia e das suas variantes "neuronais" ou sociais - e o sujeito-efeito - aquele assujeitado ao inconsciente, da psicanálise, ou o das teorias do discurso que postulam a determinação histórica em um sentido não individual é aqui crucial." (AUTHIER-REVUZ, 1992: 16)

Fica claro, nesta passagem, como uma concepção de sujeito exclui efetivamente outra: o sujeito da psicanálise e o da psicologia são apresentados como não partilhando de propriedades relevantes: o sujeito de um campo não interessa ao outro. Não deixa de ser curioso, no entanto, que o sujeito assujeitado pelo inconsciente pode ser assujeitado simultaneamente por determinações históricas. A pergunta teórica que se poderia formular é por que não se pode reconhecer, em conjunto com essas determinações, outras tantas determinações (ou condicionantes), eventualmente, as "neuronais" (genéticas, etc.) e as "sociais". Ou elas podem ser simplesmente negadas, por não dizerem respeito a nada?

A autora explicita seu ponto de vista acrescentando que, se nos apoiamos em um sujeito como fonte intencional do sentido que ele exprime, é coerente considerar que o enunciador representa sua enunciação e o sentido que ele aí produz, e que talvez este lhe seja transparente. Mas, continua ela, se nos apoiamos em exteriores teóricos que destituem o sujeito do domínio de seu dizer (...) consideraremos que o dizer não pode ser transparente ao enunciador, ao qual ele escapa... em sua dupla determinação pelo inconsciente e pelo interdiscurso (idem, p. 17). Mesmo assim, a autora reconhece que suas análises permitem à teoria interessar-se pelas formas concretas da enunciação (tidas por outros como puras manifestações superficiais da "ilusão subjetiva", devido a seu interesse exclusivo pelos processos discursivos, considerados os verdadeiros sujeitoscausa do dizer...).

Para resumir, e para introduzir finalmente alguns fatos: a metaenunciação, a repetição, a paráfrase, a inserção parentética, etc., 
dizem respeito a fenômenos como "para falar francamente, X", "como dizem os economistas, X", "literalmente, X", "isto é, X", etc., que aparecem no fio do discurso. Como interpretá-los? Sumariamente: para a pragmática, o sujeito faz esses comentários relativamente a seu próprio discurso para tornar sua relação com o interlocutor mais bem sucedida, para evitar mal-entendidos; para a $\mathrm{AD}$, o sujeito faz tais comentários por estar em uma posição que o obriga a impedir que um discurso se confunda com outro; o sujeito não faz o que faz porque quer ou porque sabe, faz o que faz premido por determinações externas. Pensa que sabe do que fala (ilusão, etc), que comenta seu próprio discurso, mas apenas revela um espaço interdiscursivo tenso, um lugar em que a própria língua exibe seu funcionamento discursivo, longe de ser, portanto, mero instrumento à disposição de interlocutores.

\section{OS FATOS}

Antes de encarar os fatos empíricos, quero repetir a hipótese deste trabalho: os processos metaenunciativos são efeitos simultaneamente do interdiscurso e das circunstâncias. Não se trata, pois, de pôr em questão as análises efetuadas a partir dos pontos de vista da $\mathrm{AD}$, mas de acrescentar-lhe mais um tipo de determinação. Mas se trata, sim, de pôr em questão as análises pragmáticas.

Como primeiro caso, comentarei um exemplo citado em MAINGUENEAU (1987:96), a respeito do qual costumo dizer a meus alunos que quem o compreende adequadamente compreende, enfim, o que é a AD.

“... François Mitterand, buscando defender a política de rigor de seu primeiro Ministro, Laurent-Fabius, lembra a necessidade de "um crescimento sadio, isto é, um crescimento sem inflação e ancorado sobre um aparelho modernizado e fortalecido de produção"...

Maingueneau acrescenta que, com a seqüência que segue a expressão "isto é", o enunciador "bloqueia a infinidade de possíveis interpretações de sadio, fornecendo um equivalente que, em vez de 
explicitar um sentido unívoco, garantido por algum saber econômico, o constrói em sua enunciação". O que interessa destacar é que, evidentemente, não se trata de explicar a um interlocutor que não conhecesse a palavra "sadio" qual é seu significado. É evidente, por outro lado, que, se o enunciador ocupasse outra posição discursiva, a seqüência poderia ser, alternativamente, "isto é, sem desemprego", "isto é, com crescimento", etc. Este exemplo mostra muito bem o que quer dizer a $\mathrm{AD}$ quando afirma que o locutor não é a fonte de seu discurso, mas que ele enuncia a partir de uma posição. O que explica a ocorrência de uma ou de outra parafrasagem é a posição discursiva, no caso, a doutrina econômica que o enunciador adota. Este exemplo é bastante adequado para defender a hipótese de que a metaenunciação é uma questão de discurso, não de relevância, no sentido pragmático. Ou seja: a palavra comentada é "sadio" e não outra porque ela representa um ponto de encontro de várias formações discursivas e não em função das circunstâncias ou por causa de um lampejo do locutor.

Vejamos agora exemplos em que a determinação da formação discursiva não parece tão óbvia:

Numa reunião de um Colegiado de Pós-graduação, quando se
discutia a questão do tempo gasto pelos alunos para concluir os
cursos, e especialmente eventuais medidas a serem tomadas em
relação aos alunos desligados (ou seja, que perdem sua ligação com
o curso por terem ultrapassado o tempo máximo permitido pelo
regulamento), um coordenador presente comentou: “...temos
problemas com os desligados - desligados no sentido de que não
ligam para o programa...”

Como se pode ver, estão em jogo dois sentidos da palavra "desligado": 'aquele que perdeu o vínculo com a Universidade, não é mais aluno, depois de tê-lo sido', e 'aquele que não se interessa por'. É exatamente por se tratar de reunião de um colegiado de pósgraduação que são estes os dois sentido postos a funcionar. ${ }^{8}$ Portanto, estão colocados lado a lado dois discursos (o do regulamento, que é jurídico, e o do professor que ousa julgar o interesse 
dos alunos pelo curso). Nenhum dos dois discursos é, evidentemente, de autoria original do referido coordenador, ou seja, nunca ouvido antes. Mas, observe-se que há um jogo com os sentidos da palavra (jogo que não deixa de ter seu efeito cômico), pondo em primeiro plano o sentido que, dado o rumo da discussão, que se situava no campo jurídico, deveria estar em segundo plano (desligado $=$ aquele que não se interessa por $)$ - fenômeno que é característico dos chistes. A pergunta que se pode fazer é: se todas as palavras estão sujeitas ao mesmo funcionamento, por que se destaca exatamente a palavra "desligados"? A resposta poderia ser: é porque é dela que se trata, nesta circunstância, é ela que é relevante e não, por exemplo, a palavra "problemas", por mais problemática que também seja...

O exemplo seguinte parece permitir que se demonstre mais claramente a simultaneidade dos variados fatores determinantes do comentário metaenunciativo:

Durante período eleitoral recente (final de 1998), na véspera de um debate televisionado entre os dois candidatos no segundo turno ao governo do Estado de S. Paulo, um deles declarou: "Qualquer coisa que eu vá dizer eu não vou revelar hoje. Para que eu vou entregar o ouro ao bandido? E acho que a palavra "bandido" está aqui bem empregada.

A declaração foi feita pelo governador Mário Covas, quando candidato à reeleição. O adversário é Paulo Maluf, ex-governador, ex-prefeito de S. Paulo, considerado, mesmo por muitos de seus eleitores, um político corrupto. Na campanha, chegou a incorporar o slogan "Rouba, mas faz" (sob a forma menos agressiva "não é santo, mas faz"), após pesquisa qualitativa que revelou que o fato de ser considerado corrupto não lhe retirava votos; prevaleceria sua imagem de realizador (construtor de grandes obras de engenharia, em geral muito caras, provavelmente em conseqüência de superfaturamento).

Creio que temos aqui um exemplo extremamente interessante. A declaração efetua o cruzamento de um discurso que se repete (memória discursiva), não só pelo fato de que há tempos se diz que Maluf é corrupto, mas também porque o locutor emprega um 
idiomatismo, "entregar o ouro ao bandido", que significa, no contexto do debate, 'revelar a estratégia'. Mas há um outro fato relevante, o mais relevante aqui: o comentário do candidato a respeito da palavra "bandido". No idiomatismo, tomado "fora de contexto”, a palavra significa 'o outro', 'o adversário', 'o concorrente', mas o locutor sobrepõe a este funcionamento geral um sentido específico: explora um sentido "de dicionário" da palavra "bandido", subverte o idiomatismo, recupera o sentido "literal", produzindo o efeito de qualificar bastante claramente seu adversário como bandido, mas sem comprometer-se explicitamente com essa qualificação eventualmente por saber das possíveis conseqüências jurídicas decorrentes de uma acusação explícita.

O que temos, então, é o funcionamento de um discurso impessoal, corrente, veiculado por qualquer adversário de Maluf, enriquecido por fatores circunstanciais, que, estes, não necessariamente repetíveis em outra circunstância, produzem como efeito uma multiplicidade de sentidos, um dos quais interessa destacar, pelo fato de que poderia ser utilizado como exemplo típico por um pragmaticista: Covas chama - indiretamente - Maluf de bandido, e o faz através de um comentário metaenunciativo.

Creio que estamos diante de um caso claro em que o enunciador está simultaneamente no domínio típico do discurso e no domínio típico da pragmática. Sua manobra decorre de sua posição política (não pessoal, portanto), mas é também tipicamente pessoal, na medida em que explora ("usa", diria Certeau) o material discursivo para produzir um efeito específico e circunstancial.

Para aceitar esta análise, é necessário aceitar também que o sujeito tenha uma certa competência; que, mesmo atravessado pelo inconsciente e/ou pela ideologia, não está impedido de adquirir o domínio de certas regras e de poder controlar, até certo ponto, os efeitos de seu discurso, ou de fazer com que determinados elementos do discurso sofram uma inflexão específica, com efeitos circunstanciais.

Recorro a Freud para garantir boa companhia nesta posição. Em relação à questão de um certo tipo de conhecimento que se pode 
atribuir aos locutores, creio que se pode apelar para a argumentação utilizada pelo fundador da psicanálise para distinguir chistes de outras espécies do cômico. Em ambos os casos, o "material" verbal pode ser muito semelhante, pode até mesmo ser idêntico, sendo decisiva, portanto, a diferente posição do sujeito para que se possa distinguir um chiste da ocorrência de um outro tipo de cômico. Considere-se o seguinte caso analisado por Freud:

"Uma menina de três anos e meio avisa a seu irmão: 'Olha, não coma tanto pudim, senão vai ficar doente e tomar um 'Bubizin'. 'Bubizin?', pergunta a mãe, 'O que é isso?' 'Quando fico doente', disse a menina autojustificando-se, 'tenho que tomar Medizin'. A criança pensava que aquilo que o médico lhe prescrevia se chamava 'Mädi-zin' quando era para uma 'Mädi [garotinha]' e concluíra que, quando era para um 'Bubi [garotinho]', devia chamar-se 'Bubi-zin'. Esta construção assemelha-se à elaboração de um chiste verbal por similaridade fônica e podia, efetivamente, ter ocorrido como um chiste real, caso em que o acolheríamos, meio constrangidamente, com um sorriso. Como um exemplo de ingenuidade, parece-nos excelente e suscita o riso. O que é que faz a diferença entre um chiste e alguma coisa ingênua? Evidentemente, não se trata da verbalização da técnica, que seria a mesma para ambas as possibilidades, mas de um fator que, à primeira vista, parece mesmo muito remoto a elas duas. Trata-se meramente de que admitamos que o locutor pretendeu fazer um chiste [ênfase minha] ou de que suponhamos que ele - a criança - tenha tentado, de boa fé, sacar uma conclusão séria à base de sua impune ignorância." (FREUD, 1905: 209)

Como se pode ver, segundo Freud, para que um texto seja um chiste é necessário que haja a intenção de produzir um e que se conheça o que as palavras (no caso) significam e dominam algumas possibilidades de sua manipulação. Espero que não se entenda, no entanto, que basta a intenção de fazer um chiste para que um texto se torne chistoso. Isso equivaleria a desprezar praticamente toda a argumentação de Freud sobre o tema, pois que a técnica do chiste é por ele considerada fundamental. Seu domínio pelo locutor é, portanto, crucial. 
Já que estamos nesse domínio, vale assinalar que o candidato Mário Covas está certamente se divertindo no episódio, o que permitiria acrescentar um conjunto de fatores da ordem do inconsciente, sem os quais, segundo Freud, não nos divertiríamos produzindo e relatando chistes.

\section{CONCLUSÃO}

O exemplo de Freud permite exatamente argumentar que a existência do inconsciente não exclui a relevância de um certo conhecimento e de uma certa intenção: em suma, para fazer um jogo de palavras, não exclui a relevância da relevância.

Se a hipótese deste trabalho é correta, o sujeito-locutor dos enunciados comentados acima não destaca elementos da cadeia discursiva aleatoriamente. Destaca sempre aqueles que são mais relevantes naquela instância de enunciação. É neste sentido, também, que os processos de metaenunciação permitem interessar-se pelas "formas concretas da enunciação tidas [pela AD] como puras manifestações superficiais da 'ilusão objetiva'" (AUTHIER-REVUZ, 1992:17). 


\section{NOTAS}

* A apresentação deste trabalho no III Colóquio Latinoamericano de Analistas do Discurso só foi possível em virtude do suporte da FAPESP (Fundação de Apoio à Pesquisa do Estado de São Paulo), que financiou a participação do autor (Processo 99/01024-1).

${ }^{1}$ Aqui, toma-se AD em sentido bastante restrito, sem pretensão de recobrir todas as vertentes que tratam das problemáticas do discurso. Assim, a expressão se refere tipicamente à escola ligada à conjunção lingüística estruturalista, marxismo e psicanálise.

${ }^{2} \mathrm{O}$ clima intelectual da época incluía a suposição de uma teoria científica da história (científica em sentido estrito) e, no caso específico de Pêcheux, o projeto de uma teoria científica, nos mesmos moldes, do discurso - hipótese abandonada a tempo pelo próprio Pêcheux.

${ }^{3}$ A questão pode ser vista também em autores de filiação relativamente distinta, como em Khun e em Feyerabend (ver FEYERABEND 1970).

${ }^{4}$ Ver, por exemplo, POSSENTI (1997).

${ }^{5}$ No mesmo grupo, incluo pragmaticistas como Rorty e Fisch, que liberariam os leitores para fazerem o que querem com os textos, já que estes não teriam sentidos.

${ }^{6}$ No entanto, há também trabalhos como o de MATTOS (1998), dedicado a estudar a conversa.

${ }^{7} \mathrm{O}$ ponto de vista ingênuo é, evidentemente, o da pragmática, que vê aí uma manobra consciente do sujeito e não uma imposição da formação discursiva ou a heterogeneidade constitutiva da língua e do discurso, menos ainda a ação indisfarçável do interdiscuso.

${ }^{8}$ Considerando-se as informações de um dicionário, outros sentidos diriam respeito ao domínio da eletricidade, da construção civil, da rede de transportes, das relações amorosas, etc. 


\section{REFERÊNCIAS BIBLIOGRÁFICAS}

ALTHUSSER, L., BALIBAR, È. Lire Le Capital. Paris: Maspero, 1969.

AUTHIER-REVUZ, J. Heterogeneidade(s) enunciativa(s). Cadernos de Estudos Lingüisticos, 39, IEL/UNICAMP, p. 25-42, 1982.

AUTHIER-REVUZ, J. As não-coincidências do dizer e sua representação metaenunciativa - estudo lingüístico e discursivo da modalização autonímica. In: Palavras incertas; as não-coincidências do dizer. Campinas: Editora da Unicamp, 1992. p.13-28.

CERTEAU, M. de A invenção do quotidiano; as artes de fazer. Petrópolis: Vozes, 1990.

DUCROT, O. Esboço de uma teoria polifônica da enunciação. In: O dizer e o dito. Campinas: Editora Pontes, 1984. p.161-218.

FEYERABAND, P. Consolando o especialista. In: LAKATOS, I., MUSGRAVE, A. A crítica e o desenvolvimento do conbecimento. São Paulo: Editora Cultrix Editora da Univesidade de São Paulo, 1970. p.244-284.

FREUD, S. Os chistes e sua relação com o inconsciente. Rio de Janeiro: Imago, 1905.

GADET, F., HAK, T. (Orgs) Por uma análise automática do discurso. Campinas: Editora da Unicamp, 1990. p. 61-161.

LEVINSON, S. C. Pragmatics. Cambridge: University Press, 1983.

MAINGUENEAU, D. Genèses du discours. Breuxelles: Pierre Mardaga, Editeur, 1984.

MAINGUENEAU, D. Novas tendências em análise do discurso. Campinas: Editora da Unicamp - Editora Pontes, 1987.

MATTOS, M. A. de. Dispersão e memória no quotidiano. São Paulo: Martins Fontes, 1998.

PÊCHEUX, M. (1969). A análise automática do discurso. In: GADET, F., HAK, T. (Orgs), 1990, p. 61-161.

PÊCHEUX, M., FICHANT, M. Sobre a bistória das ciências. São Paulo: Editora Mandacaru, 1969.

POSSENTI, S. Por uma análise do discurso mais complexa. In: BOLÍVAR, A., BENTIVOGLIO, P. (Eds). Caracas, Actas del I Coloquio de analistas del discurso. Universidad Central de Venezuela-Aled, p.264-272, 1997. 